$$
\begin{aligned}
& \text { SAN098-0304C } \\
& \text { SAND- }-98-0304 C
\end{aligned}
$$

Submitted to J. Electron. Mat., Proceedings of ICOMVPE-9

\title{
OMVPE Growth and Gas-Phase Reactions of AIGaN for UV Emitters
}

J. Han, ' J. J. Figiel, M. H. Crawford, M. A. Banas, M. E. Bartram, and R. M. Biefeld Sandia National Laboratories, Albuquerque, New Mexico 87185-0601

\author{
Y. K. Song and A. V. Nurmikko \\ Division of Engineering, Brown University, Providence, RI
}

CONF- $980658--$

RECEIVED

JUN 081998

$08 \mathrm{TI}$

\begin{abstract}
Gas-phase parasitic reactions among TMG, TMA, and $\mathrm{NH}_{3}$, are investigated by monitoring of the growth rate/incorporation efficiency of $\mathrm{GaN}$ and AlN using an in-situ optical reflectometer. It is suggested that gas phase adduct $\left(\mathrm{TMA}: \mathrm{NH}_{3}\right)$ reactions not only reduce the incorporation efficiency of TMA but also affect the incorporation behavior of TMGa. The observed phenomena can be explained by either a synergistic gas-phase scavenging effect or a surface site-blocking effect. Relatively low reactor pressures (30-50 Torr) are employed to grow an AlGaN/GaN QW p-n diode structure. The UV emission at $354 \mathrm{~nm}(\mathrm{FWHM} \sim 6 \mathrm{~nm})$ represents the first report of LED operation from an indium-free GaN QW diode.
\end{abstract}

Distribution of this docunient is UnLIMIted $h$ MASTER

*Corresponding author: jhan@sandia.gov 


\section{DISCLAIMER}

This report was prepared as an account of work sponsored by an agency of the United States Government. Neither the United States Government nor any agency thereof, nor any of their employees, makes any warranty, express or implied, or assumes any legal liability or responsibility for the accuracy, completeness, or usefulness of any information, apparatus, product, or process disclosed, or represents that its use would not infringe privately owned rights. Reference herein to any specific commercial product, process, or service by trade name, trademark, manufacturer, or otherwise does not necessarily constitute or imply its endorsement, recommendation, or favoring by the United States Government or any agency thereof. The views and opinions of authors expressed herein do not necessarily state or reflect those of the United States Government or any agency thereof. 


\section{INTRODUCTION}

$\mathrm{GaN}$ is known ${ }^{1}$ to exhibit a high equilibrium nitrogen vapor pressure at temperatures typically employed $\left(1000\right.$ to $\left.1100^{\circ} \mathrm{C}\right)$ during the MOCVD process which demands the supply of a substantial amount of ammonia $\left(\mathrm{NH}_{3}\right)$ to minimize the loss of surface nitrogen. However, a high partial pressure of $\mathrm{NH}_{3}$ in the reaction chamber enhances the formation of the Lewis acidbase complexes (adducts) between $\mathrm{NH}_{3}$ and metal-organic molecules (such as trimethylgallium, TMGa) in the gas phase. Gas-phase pre- (or parasitic) reactions often complicate the growth chemistry by adding extra steps in or even diverting precursor dissociation on the deposition surface. $^{2}$ In many cases such gas-phase pre-reactions can also cause the depletion of reactants when large oligomers resulting from adduct decomposition and having with low vapor pressures can not be transported efficiently in the vapor stream.

So far, most of the efforts in III-nitrides have focused on visible (blue and green) light emitters employing InGaN as the active layers. The AlGaN alloy system serves a dual purpose in ultraviolet (UV) optoelectronics and power electronics. Gas-phase interactions during organometallic vapor phase epitaxy (OMVPE) between $\mathrm{NH}_{3}$ and the two most commonly employed group III metal-organic precursors, TMGa and trimethylaluminum (TMAl), need to be understood. Thon and $\mathrm{Kuech}^{3}$ studied the gas-phase reaction of TMGa with $\mathrm{NH}_{3}$ and observed a rapid ( $<1 \mathrm{sec}$ ) formation of adduct compound, $\left(\mathrm{CH}_{3}\right)_{3} \mathrm{Ga}: \mathrm{NH}_{3}$. Decomposition products related

to a possible oligomer product, such as $\left[\left(\mathrm{CH}_{3}\right)_{2} \mathrm{Ga}: \mathrm{NH}_{2}\right]_{\mathrm{n}}$, were suggested to result from a methane-elimination reaction. The presence of the (TMGa: $\left.\mathrm{NH}_{3}\right)$ adducts, nevertheless, does not necessarily have to influence significantly the decomposition of TMGa or the incorporation of $\mathrm{Ga}$ as judged by the relative insensitivity of $\mathrm{GaN}$ growth rates versus $\mathrm{NH}_{3}$ pressures. ${ }^{4}$ 
TMAl has been observed ${ }^{5}$ to react with $\mathrm{NH}_{3}$ into a white crystalline solid at and below room temperature. Chen et al. ${ }^{4}$ showed that the $\mathrm{Al}$ incorporation (using TMAl) during MOCVD of $\mathrm{AlGaN}$ strongly depends on the growth pressure which could be described by a bi-molecular chemical reaction. It is generally accepted that the TMAl: $\mathrm{NH}_{3}$ preaction is manifested by a reduced $\mathrm{Al}$ incorporation efficiency and a sub-linear relationship between the $\mathrm{Al}$ compositions in the gas and solid phases during the growth of AlGaN. Various measures such as special gasinjection schemes, ${ }^{6}$ short inlet-susceptor separation, ${ }^{7}$ higher gas velocity, ${ }^{8}$ and reduced reactor pressures ${ }^{4}$ have been adopted to alleviate the pre-reaction between TMAl and $\mathrm{NH}_{3}$ even though the information as to the degree to which gas-phase reactions occur under growth conditions has not been well-established.

In this paper we intend to illustrate experimentally the cause-effect of the incorporation of Al under a range of OMVPE growth conditions. The effect of TMA: $\mathrm{NH}_{3}$ reaction on the growth rate was studied in situ using an optical reflectance monitor ${ }^{9}$ which enables us to delineate the susceptibility of the growth rate to pre-reactions over a wide range of gas compositions. We will show that the formation of (TMA: $\mathrm{NH}_{3}$ ) adduct not only depletes TMA from the vapor state but also inhibits the incorporation of TMG (by as much as $60 \%$ ). Once the extent of gas-phase reaction was mapped out over growth parameter space, we attempted the growth of $\mathrm{AlGaN} / \mathrm{GaN}$ heterostructures. The growth and device fabrication of a short-wavelength indium free GaN quantum well (QW) UV LED, with an emission wavelength at $354 \mathrm{~nm}$, will be reported in this paper.

\section{EXPERIMENTAL}

GaN/AlGaN was grown in a high speed rotating $(\sim 1000 \mathrm{rpm})$ MOCVD reactor (diameter of the quartz chamber is $\left.4.75^{\prime \prime}\right)$. Two-inch basal plane sapphire wafers were placed on 
molybdenum (Mo) susceptor, which is RF inductively heated using a SiC-coated graphite coupling block. Temperature was monitored by a pyrometer focusing on the Mo susceptor surface nearly co-planar with the wafer surface. $\mathrm{NH}_{3}, \mathrm{TMGa}$, and TMAl were used as the $\mathrm{N}, \mathrm{Ga}$, and $\mathrm{Al}$ precursors, respectively. Hydrogen $\left(\mathrm{H}_{2}\right)$ was used as the carrier gas and also to supplement the $\mathrm{NH}_{3}$ in making up the required flow rate as determined by the reactor pressure and wafer rotating speed. ${ }^{10}$ Metal-organic precursors were separated from hydride gases before being injected into top of the growth chamber. The reflectometer uses a tungsten lamp as a light source, illuminating a spot (of $6 \mathrm{~mm}$ in diameter) on the sample surface through the reactor port window. Standard two-step growth $\left(550\right.$ and $1050{ }^{\circ} \mathrm{C}$ for the low and high temperatures, respectively) with $\mathrm{GaN}$ low-temperature buffer layer was used in this work.

\section{ALGAN GAS PHASE REACTIONS}

We have reported ${ }^{11}$ that the in-situ reflectance monitor can provide information on surface roughening, growth rates, and even AlGaN alloy compositions. During our initial attempt of growing AlGaN, it was observed that the introduction of TMAl into the reactor (while leaving TMGa and $\mathrm{NH}_{3}$ flow rates constant) caused an increase of the periodicity (of the reflectance oscillations) during the AlGaN growth, implying a decrease in the growth rate.

Taking advantage of in-situ growth rate monitoring, we have now conducted a series of experiments aimed at illustrating the complex nature of the gas-phase reactions when both TMGa and TMAl are used with $\mathrm{NH}_{3}$. Figure 1 shows a typical reflectance trace during a particular study of the gas-phase reactions. In this experiment, the TMGa and TMAl flow rates were fixed at around $60 \mu \mathrm{mole} / \mathrm{min}$. TMGa, TMAl, and both TMGa and TMAl were open sequentially to allow a measurement of the growth rates of GaN (region (i)), AlN (region (ii)), and AlGaN (region (iii)), respectively, at a given gas composition (a layer of GaN was inserted after AlN 
growth to improve the surface morphology and verify the measured growth rate of $\mathrm{GaN}$ ). We then changed the gas composition (partial pressures of $\mathrm{H}_{2}$ and $\mathrm{NH}_{3}$ independently, from region (A) to (B) in Fig. 1) and repeated the same valve operation. (The total reactor pressure equals the sum of the partial pressures of $\mathrm{H}_{2}$ and $\mathrm{NH}_{3}$ since TMGa and TMAl flows contribute negligible pressures.) Such an in-situ probe allows a single growth run to provide the data necessary to construct three-dimensional plots of the growth rates of GaN (Fig. 2(a)), AlN (Fig. 2(b)), and AlGaN (Fig. 2(c)) versus partial pressures of both $\mathrm{H}_{2}$ and $\mathrm{NH}_{3}$.

It is clear from Fig. 2(a) that the reported gas phase reactions between $\mathrm{TMGa}$ and $\mathrm{NH}_{3}$ do not result in much (if any) of a decrease in growth efficiency when the $\mathrm{H}_{2}$ partial pressure is less than 20 Torr. The decreased growth rate shown at higher $\mathrm{H}_{2}$ pressure may be due to the etching of $\mathrm{GaN}$ by a $\mathrm{H}_{2}$ surface reaction. ${ }^{12}$ Alternatively, this may be due to an indirect effect of decreasing the rate of the decomposition reaction ${ }^{13}$ needed to compensate for the loss of nitrogen at high temperatures.' The trend of the growth rate of AlN versus $\mathrm{NH}_{3}$ shows distinctly different behavior. An increase of $\mathrm{NH}_{3}$ (with $\mathrm{H}_{2}$ pressures below 20 Torr) leads to a rapid decrease of AlN incorporation. We note that the above observation is in qualitative agreement with the previous report ${ }^{4}$ of a bi-molecular reaction between $\mathrm{TMAl}$ and $\mathrm{NH}_{3}$.

The growth rate of AlGaN (with both TMGa and TMAl open) is shown in Fig. 2(c). It is interesting to note that the measured growth rate of AlGaN is always less than the sum of the growth rates of the individual binary compounds. An "interaction parameter" $\Omega$ is therefore defined as $\left(\mathrm{GR}_{\mathrm{AlGaN}} /\left(\mathrm{GR}_{\mathrm{AlN}}+\mathrm{GR}_{\mathrm{GaN}}\right)\right)$ which is plotted in Fig. 2(d). An $\Omega$ value approaching unity suggests an independent and additive incorporation of TMAl and TMGa. An $\Omega$ much less than unity implies that additional interactions between the respective adduct compounds, either in the gas phase or on the gas-solid interface, have inhibited the incorporation of certain species. 
Comparing Fig. 2(b) and 2(d), one could argue that the reduction of $\Omega$ follows the general trend of the reduction of AIN growth rates (which in turn suggests an increase in gas-phase adduct reactions related to species such as $\left.\left[\left(\mathrm{CH}_{3}\right)_{2} \mathrm{Al}: \mathrm{NH}_{2}\right]_{n}{ }^{14}\right)$. Such reactions are seen to inhibit the incorporation of $\mathrm{TMGa}$, down to less than $40 \%$ at an $\mathrm{NH}_{3}$ partial pressure of 58 Torr. We speculate that the reduction of TMGa incorporation is due to either a scavenging effect of TMAl: $\mathrm{NH}_{3}$ adducts or their reaction products on TMGa (or TMGa: $\mathrm{NH}_{3}$ adducts) in the gas phase. Alternatively, this may be due to a site-blocking effect ${ }^{15}$ in which the competitive adsorption of TMAl: $\mathrm{NH}_{3}$ decomposition products decreases the TMGa reraction rate on the surface.

Ideally the Lewis-base precursors should be separated physically for as long as possible from the Lewis-acid precursors before they reach the growth surface. Implementation of this concept, however, is often at the expense of growth uniformity over a large area due to the lack of gas mixing. The spacing between inlet and growth surface essentially determines the reaction time. In our system, the separation between the inlet and the susceptor surface is around 4". Under typical growth conditions, this amounts to a potential reaction time in the gas-phase of $\sim 1$ second, which serves to emphasize the facile nature of $\mathrm{TMAl}$ : $\mathrm{NH}_{3}$ reaction. Another parameter one could vary is the partial pressures of the reactants. A lower reactor or $\mathrm{NH}_{3}$ pressure not only reduces the chemical reaction rate but also increases the flow velocity, which in turn reduces the interaction time. It is worth noting that both thermodynamics calculations ${ }^{12}$ and kinetics arguments ${ }^{16}$ suggest the need to maintain minimum values of $\mathrm{V} / \mathrm{mI}$ flow ratios and $\mathrm{NH}_{3}$ partial pressures based on morphological, structural, and optical criteria.

ALGAN/GAN QW UV LEDS 
AlGaN UV LED structures were attempted once the information of the gas-phase prereaction of TMAl: $\mathrm{NH}_{3}$ had been established. It is worth noting that there has been no report, to the best of our knowledge, on the AlGaN/GaN QW p-n junction LEDs thus far. Photoluminescence (PL) has been applied to undoped ${ }^{17}$ and Si-doped ${ }^{18}$ AlGaN/GaN quantum wells (QWs) with linewidths varying from 80 to $110 \mathrm{meV}$ at room temperature. Stimulated emission by optical pumping was also achieved in the latter report. Both Amano et al. ${ }^{19}$ and Kuga et al. ${ }^{20}$ have reported $\mathrm{AlGaN} / \mathrm{GaN}$ double heterostructure (DH) diodes with emission peaks centered around 375 and $420 \mathrm{~nm}$, respectively. In both cases the widths of emission peaks are in excess of $250 \mathrm{meV}$ (or $40 \mathrm{~nm}$ ), indicative of recombination through localized centers.

The LED structure consists of a $3 \mu \mathrm{m} \mathrm{GaN}: \mathrm{Si}\left(\mathrm{n} \sim 2 \times 10^{18} \mathrm{~cm}^{-3}\right)$ grown on sapphire using a LT GaN buffer layer, an $\mathrm{Al}_{0.2} \mathrm{Ga}_{0.8} \mathrm{~N}: \mathrm{Si}\left(\mathrm{n} \sim 2 \times 10^{18} \mathrm{~cm}^{-3}\right)$ barrier layer of $0.1 \mu \mathrm{m}$ thick, four $\mathrm{GaN}$ quantum wells $\left(\sim 30 \AA\right.$ undoped) separated by undoped $\mathrm{Al}_{0.2} \mathrm{Ga}_{0.8} \mathrm{~N}$ barrier layers $(\sim 70 \AA)$, a p$\mathrm{Al}_{0.2} \mathrm{Ga}_{0.8} \mathrm{~N}\left([\mathrm{Mg}] \sim 1.0 \times 10^{20} \mathrm{~cm}^{-3}\right)$ of $0.1 \mu \mathrm{m}$ thick, a $\mathrm{p}-\mathrm{Al}_{0.1} \mathrm{Ga}_{0.9} \mathrm{~N}\left([\mathrm{Mg}] \sim 1 \times 10^{20} \mathrm{~cm}^{-3}\right)$ layer of $0.2 \mu \mathrm{m}$ thick to help current spreading, and a $\mathrm{p}-\mathrm{GaN}\left([\mathrm{Mg}] \sim 1 \times 10^{20} \mathrm{~cm}^{-3}\right)$ contact layer of $0.1 \mu \mathrm{m}$ thick. Step-graded regions were introduced between each composition change except the QW region. For the SCH structure reported here, the LT GaN and the Si-doped $\mathrm{GaN}$ were grown at 140 Torr, the rest of the structure was grown between 30 to 40 Torr. After growth the AlGaN/GaN SCH sample was annealed in the reactor at $850^{\circ} \mathrm{C}$ under flowing nitrogen (140 Torr) for $20 \mathrm{~min}$ to activate the $\mathrm{Mg}$ acceptors. An additional anneal was performed outside of the reactor at $1050{ }^{\circ} \mathrm{C}$ for $15 \mathrm{sec}$ in nitrogen. The sample was etched (using inductively-coupled plasma etching) $1.2 \mu \mathrm{m}$ deep to expose the $\mathrm{n}-\mathrm{GaN}$ region. $\mathrm{Ni} / \mathrm{Au}$ and $\mathrm{Ti} / \mathrm{Al}$ were employed as $\mathrm{p}$ and n-type contacts, respectively. 
Figure 3(a) shows the current-voltage (I-V) characteristics of a processed diode with a mesa diameter of $100 \mu \mathrm{m}$. The top p-type contact has a circular ring pattern to facilitate light emission from the center of the mesa. We note, however, that the limited p-type conductivity in $\mathrm{GaN}$ and AlGaN significantly limits lateral current spreading and the effective device area is much less than the physical dimension of the mesa. The forward turn-on occurs at around $4 \mathrm{~V}$. Electroluminescence (EL) is collected using a $200 \mu \mathrm{m}$ core fiber positioned at about $2 \mathrm{~mm}$ from the top of the device. Figure 3(b) shows the EL spectrum a $5 \mathrm{~mA}$ injection level. The emission at $354 \mathrm{~nm}$ agrees well with the PL peak position reported earlier, ${ }^{17}$ and is the shortest wavelength reported from a GaN-based light emitting diode. The FWHM of the emission peak is around 6 $\mathrm{nm}$, which compares favorably with the reports of 30 to $45 \mathrm{~nm}$ from $\mathrm{GaN}$-based $\mathrm{DH}$ diodes. We are in the process of measuring the integrated light output power as well as the quantum efficiency, and the results will be reported elsewhere.

\section{CONCLUSION}

In conclusion, we have studied the gas-phase reactions during the OMVPE growth of AlGaN. The presence of $\left[\mathrm{TMA}_{\mathrm{NH}}\right]$ adduct was found to influence and hinder the incorporation of TMGa, possibly through a gas-phase scavenging or surface site-blocking effect. The observed parasitic reactions can be alleviated by configuring the reactor design or operating at a reduced pressure. An $\mathrm{AlGaN} / \mathrm{GaN}$ p-n QW LED was grown at reduced reactor pressure regime. The observed UV emission at $354 \mathrm{~nm}$ represents the shortest wavelength emission from a GaN-based injection device.

\section{ACKNOWLEDGEMENTS}

Discussions with H. Amano (Meijo University), W. G. Breiland, and A. F. Wright are acknowledged. Sandia is a multiprogram laboratory operated by Sandia Corporation, a Lockheed 
Martin Company, for the United States Department of Energy under Contract DE-AC0494AL85000. 


\section{FIGURE CAPTIONS}

Figure 1. A portion of reflectance trace during a gas-phase reaction study. Regions (i), (ii), and (iii) correspond to GaN, AlN, and $\mathrm{AlGaN}$, respectively.

Figure 2. The measured growth rates of (a) GaN, (b) AlN, and (c) AlGaN (from Figure 1) versus $\mathrm{H}_{2}$ and $\mathrm{NH}_{3}$ partial pressures. A plot of the interaction parameter $\Omega$ (refer to text for definition) versus $\mathrm{H}_{2}$ and $\mathrm{NH}_{3}$ is shown in (d).

Figure 3. Forward I-V characteristics (a) and emission spectrum (b) of an AlGaN/GaN p-n diode structure. 


\section{REFERENCES}

${ }^{\prime}$ Z. A. Munir and A. W. Searcy, J. Appl. Phys. 42, 4223 (1965); C. D. Thurmond and R. A. Logan, J. Electrochem. Soc. 119, 622 (1972); A. Koukitu, N. Takahashi, and H. Seki, Jpn. J. Appl. Phys. 36, L1136 (1997).

${ }^{2}$ R. H. Moss, J. Cryst. Growth 68, 78 (1984).

${ }^{3}$ A. Thon and T. F. Kuech, Appl. Phys. Lett. 69, 55 (1996).

${ }^{4}$ C. H. Chen, H. Liu, D. Steigerwald, W. Imler, C. P. Kuo, M. G. Craford, M. Ludowise, S. Lester, and J. Amano, J. Electron. Mat. 25, 1004 (1996).

${ }^{5}$ L. V. Interrante, L. E. Carpenter II, C. Whitmarsh, W. Lee, M. Garbauskas, and G. A. Slack, Mat. Res. Soc. Proc. 73, 359 (1986).

${ }^{6}$ S. Nakamura, Jpn. J. Appl. Phys. 30, 1348 (1991); M. Matloubian and M. Gershenzon, J. Electron. Mat. 14, 633 (1985).

${ }^{7}$ W. Van der Stricht, I. Moerman, P. Demeester, J. A. Crawley, and E. J. Thrush, J. Cryst. Growth 170, 344 (1997).

${ }^{8}$ Y. Koida, H. Itoh, N. Sawaki, I. Akasaki, and M. Hashimoto, J. Electrochem. Soc. 133, 1956 (1986).

${ }^{9}$ J. Han, T. -B. Ng, R. M. Biefeld, M. H. Crawford, and D. M. Follstaedt, Appl. Phys. Lett. 71, 3114 (1997).

${ }^{10}$ W. G. Breiland and G. H. Evans, J. Electrochem. Soc. 138, 1806 (1991).

${ }^{11}$ T. -B. Ng, J. Han, R. M. Biefeld, and M. V. Weckwerth, J. Electron. Mat. 27, 190 (1998).

${ }^{12}$ A. Koukitu, N. Takahashi, and H. Seki, Jpn. J. Appl. Phys. 36, L1136 (1997).

${ }^{13}$ M. E. Bartram (unpublished) 
${ }^{14}$ L. V. Interrante, G. A. Sigel, M. Garbauskas, C. Hejna, and G. A. Slack, Inorg. Chem. 28, 252 (1989).

${ }^{15}$ O. Briot, J. P. Alexis, B. Gil, and R. L. Aulombard, Mat. Res. Soc. Symp. Proc. 395, 207 (1996).

${ }^{16}$ D. D. Koleske, A. E. Wickenden, R. L. Henry, W. J. Desisto, and R. J. Gorman, Mat. Res. Soc. Symp. Proc. Fall 1997, D5.27.

${ }^{17}$ M. Smith, J. Y. Lin, H. X. Jiang, A. Salvador, A. Botchkarev, W. Kim, and H. Morkoc, Appl. Phys. Lett. 69, 2453 (1996).

${ }^{18}$ T. J. Schmidt, X. H. Yang, W. Shan, J. J. Song, A. Salvador, W. Kim, O. Aktas, A. Botchkarev, and H. Morkoc, Appl. Phys. Lett. 68, 1820 (1996).

${ }^{19}$ I. Akasaki and H. Amano, Extended Abstracts of the 1992 International Conference on Solid State Devices and Materials, Tsukuba, p327 (1992).

${ }^{20}$ Y. Kuga, T. Shirai, M. Haruyama, H. Kawanishi, and Y. Suematsu, Jpn. J. Appl. Phys. 34, 4085 (1995). 


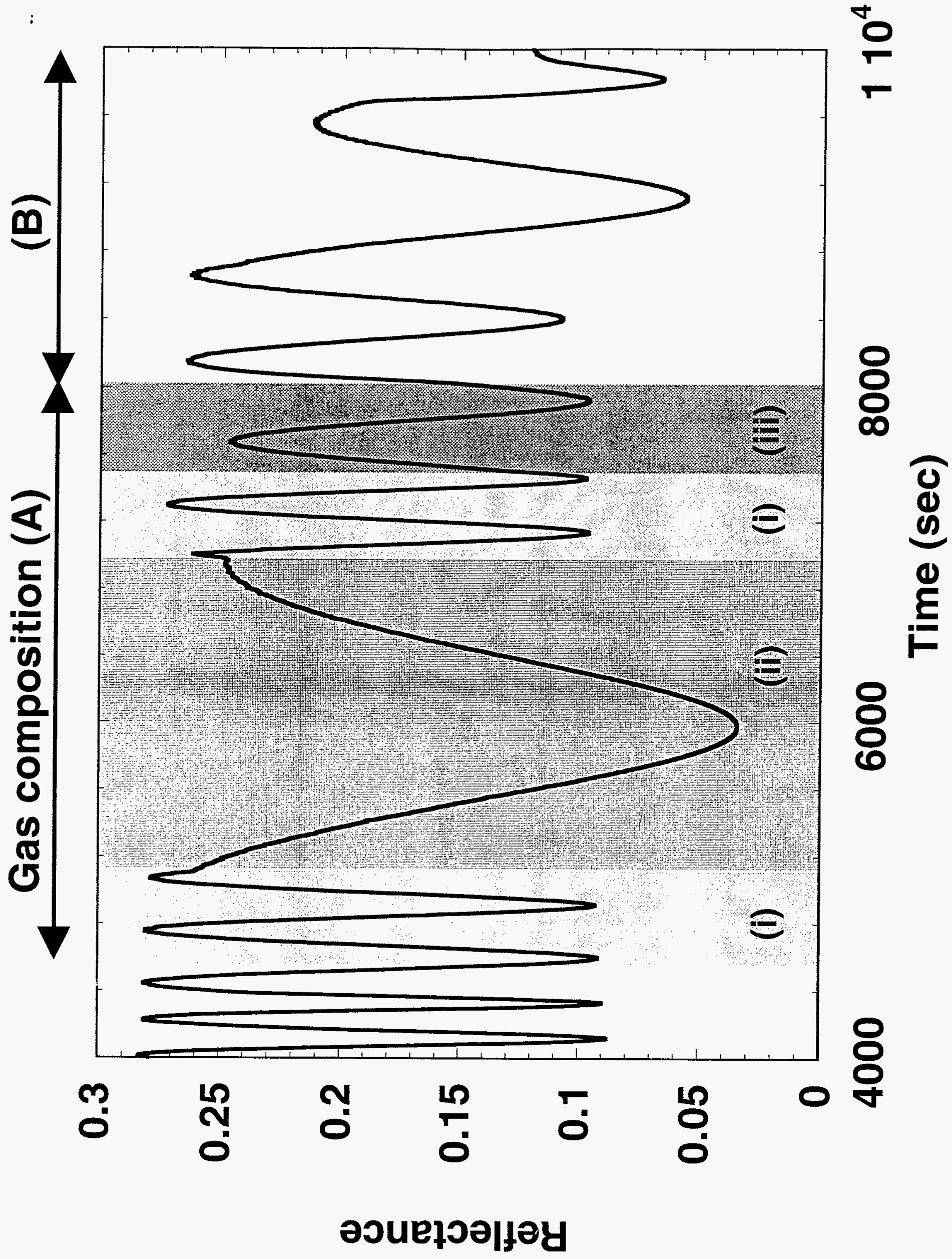




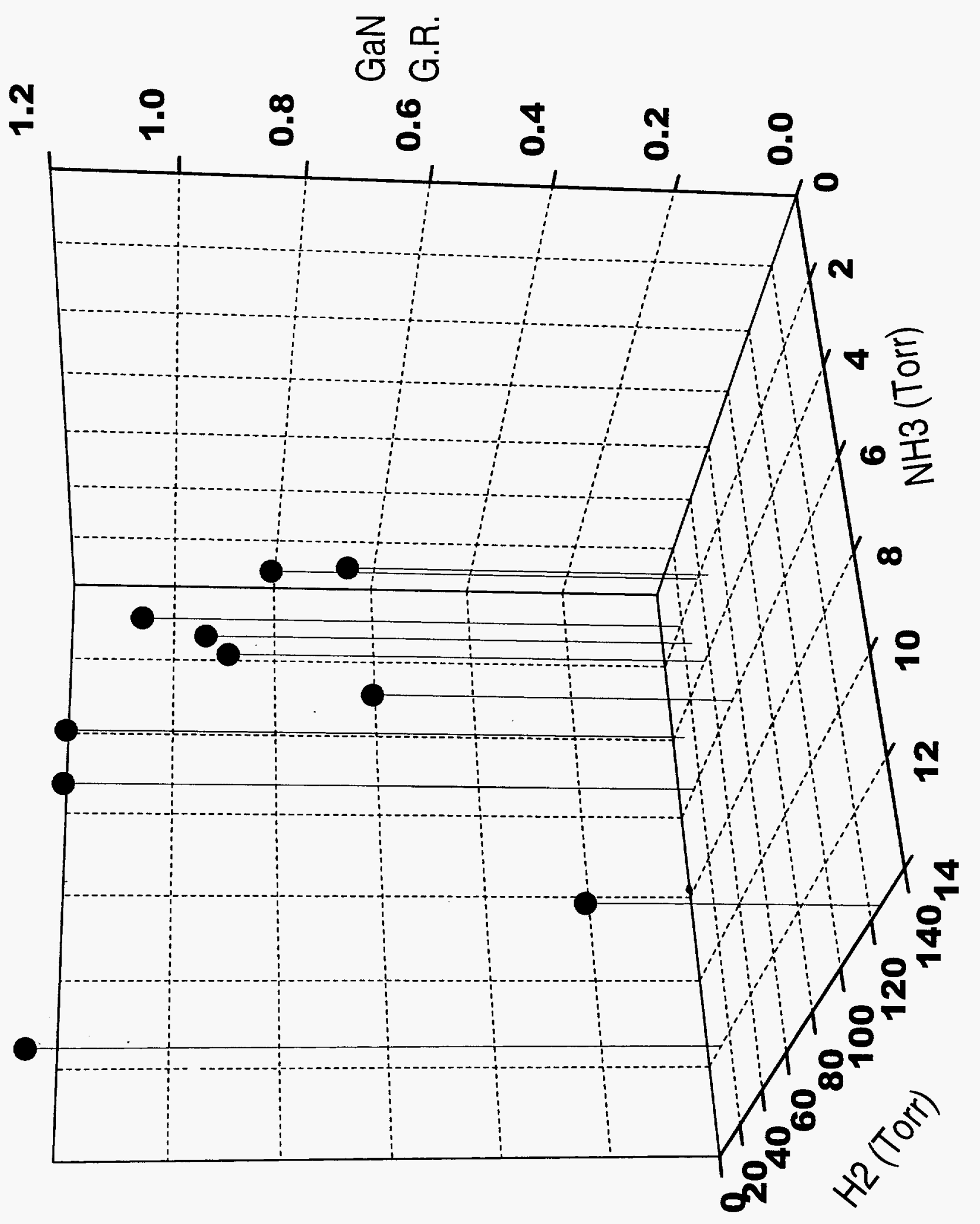




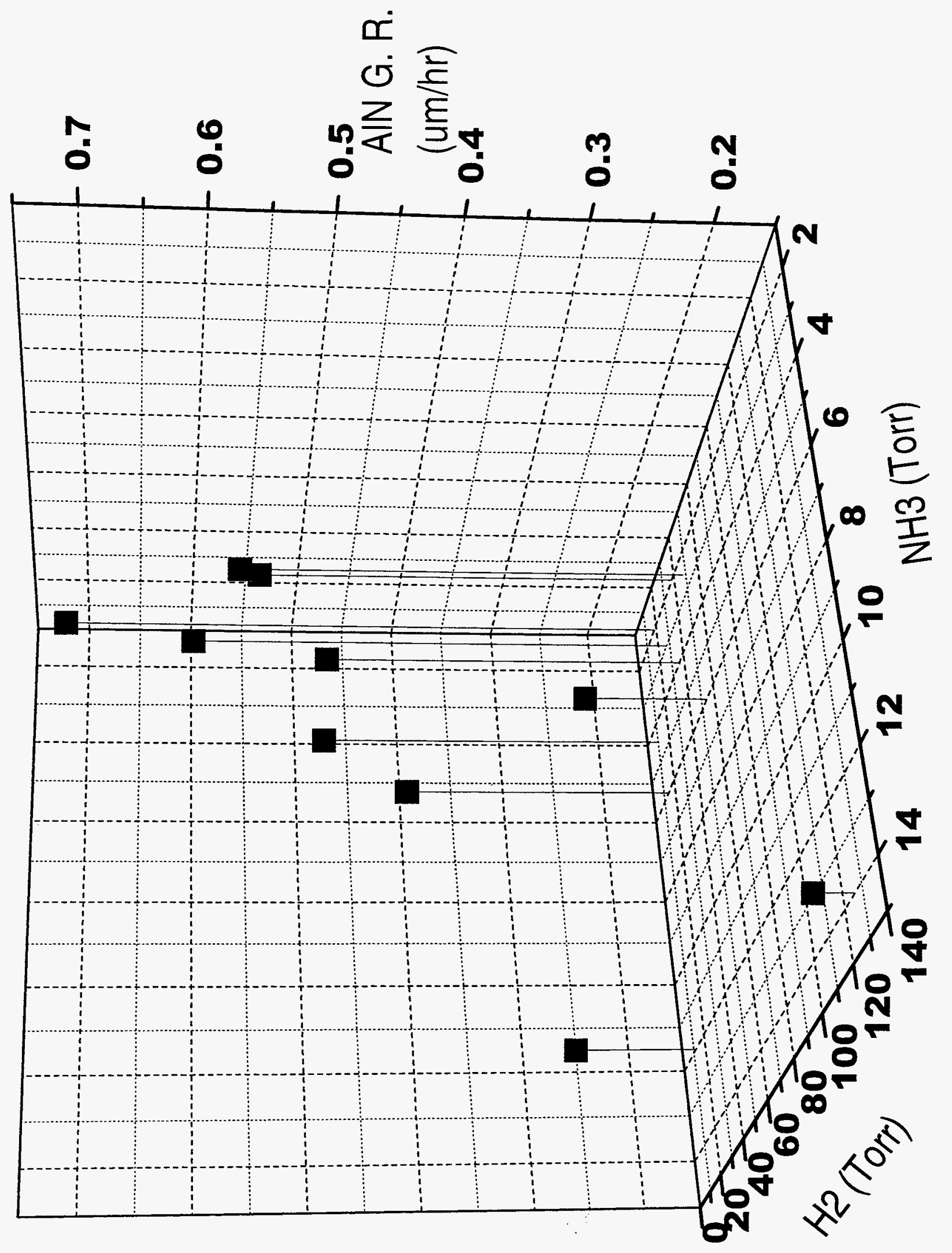




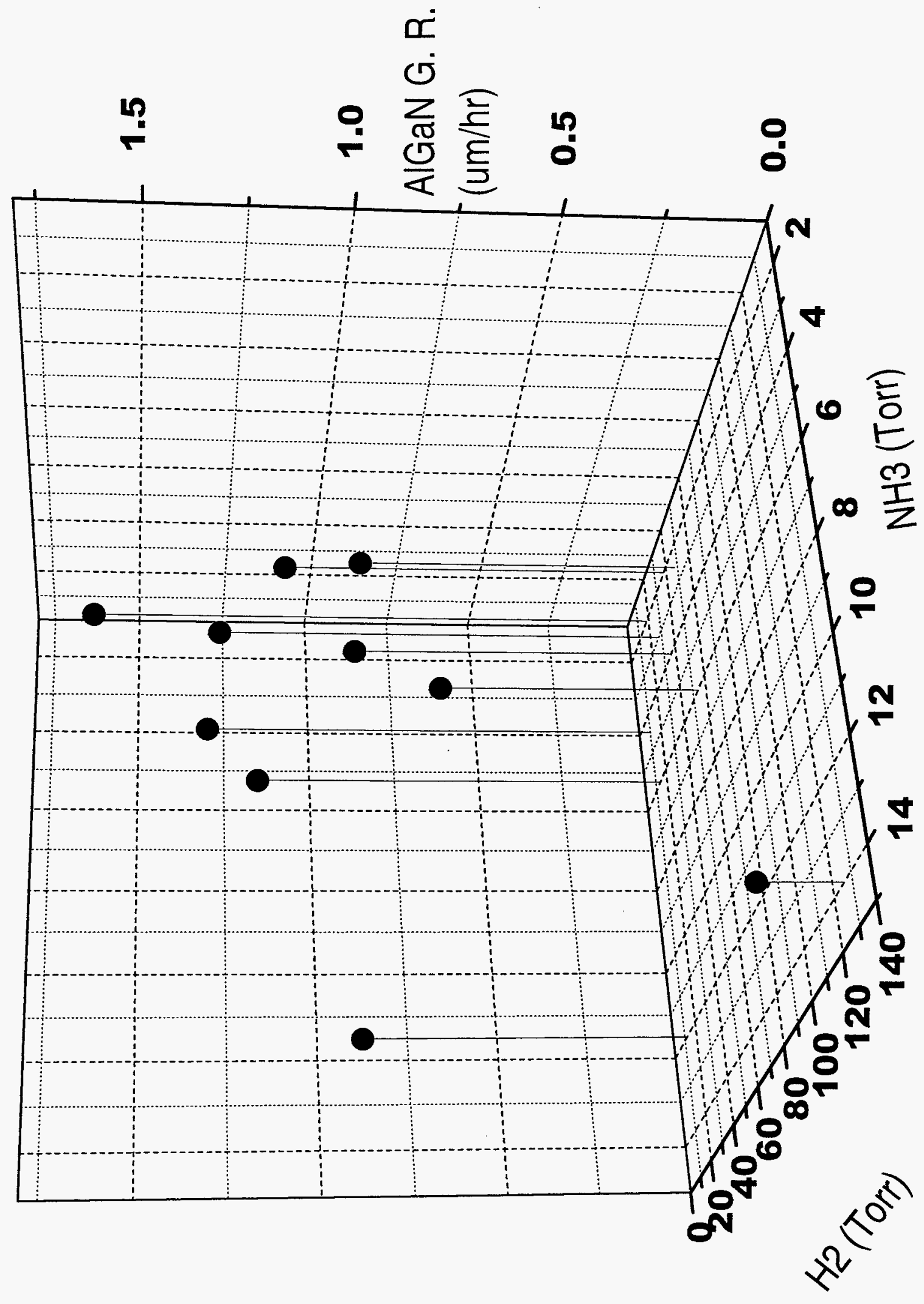




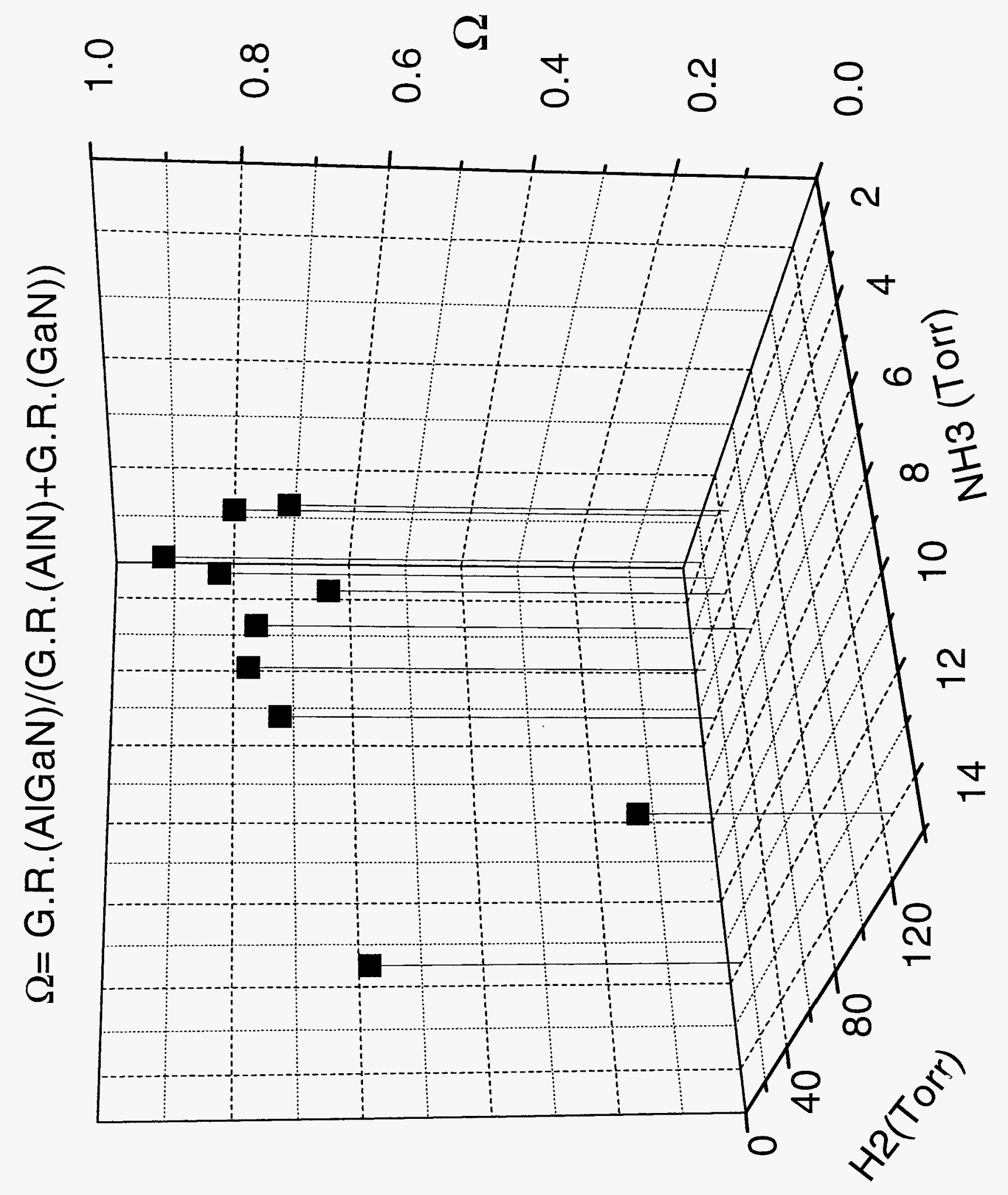


4

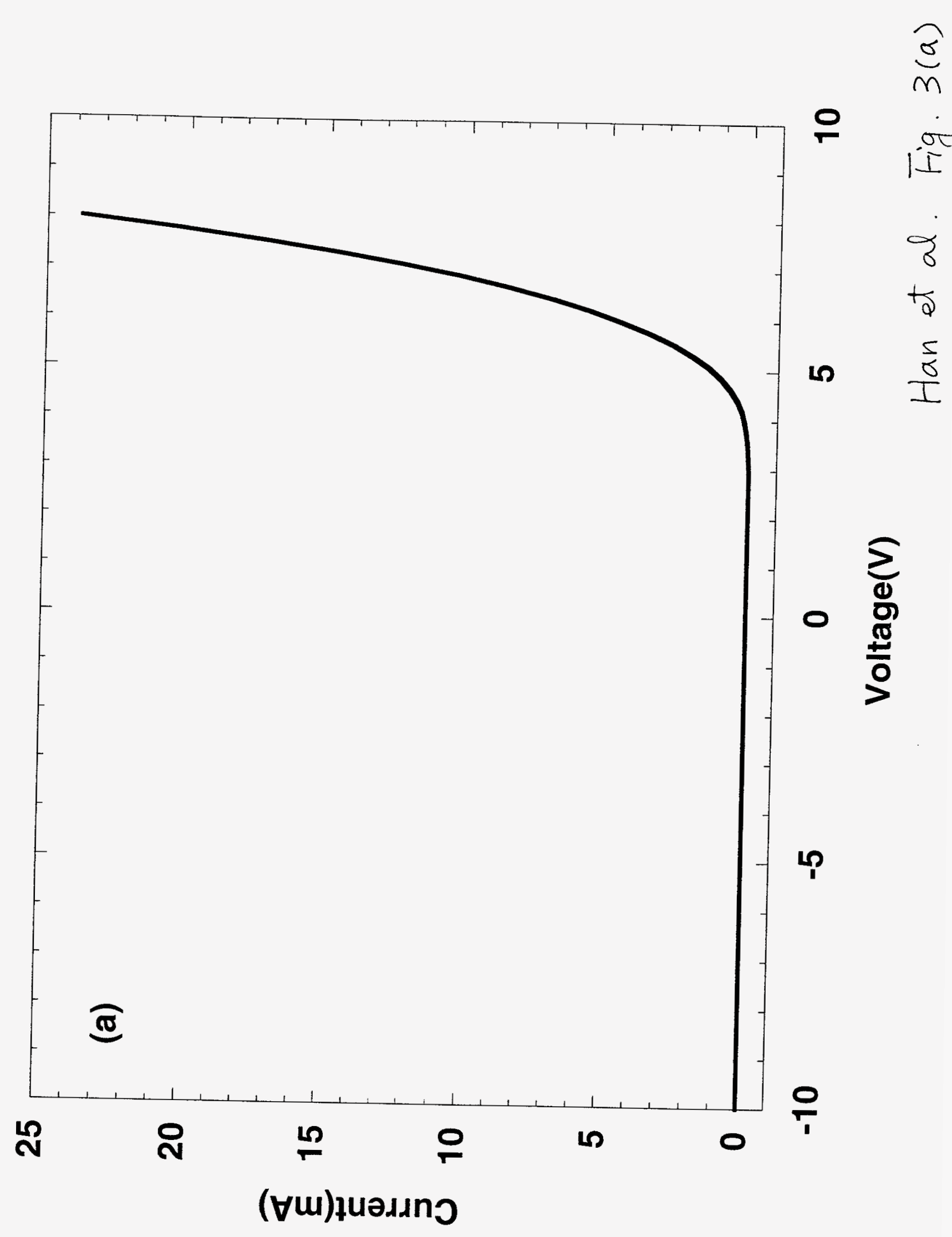




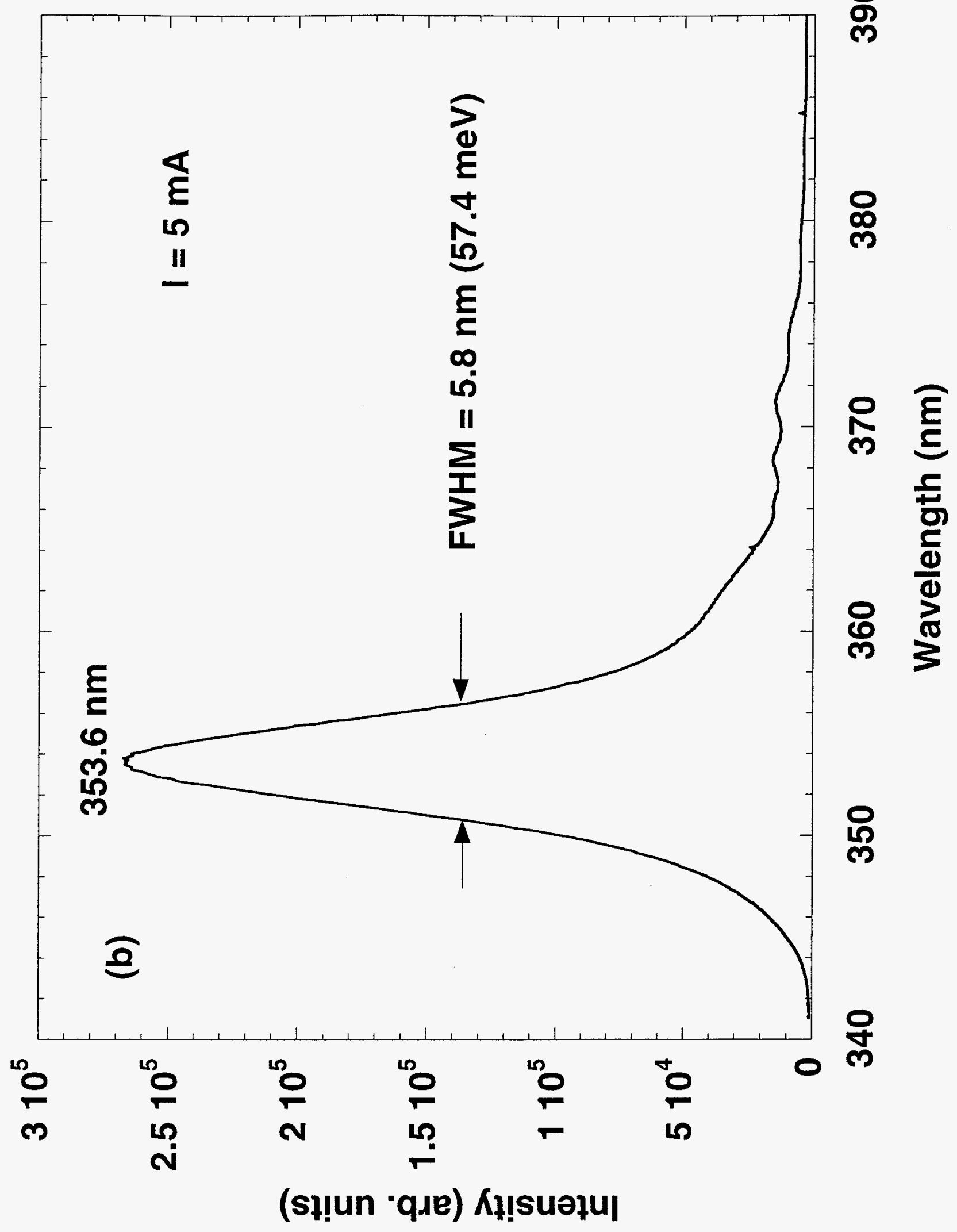




\section{M98005535 \\ ||||||||||||||||||||||||||||||||||||||||||||||}

Report Number (14) $\frac{94 D D--98-0304 C}{\text { CONF-980658 - }}$

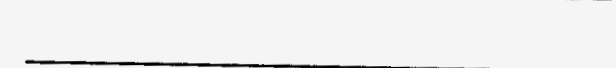

Publ. Date (11)

Sponsor Code (18) DP, XF
UC Category (19) UC-704, DOE/ER

19980702015 